\title{
The Influence of Gender, Sports Type and Training Experience on Cognitive Functions in Adolescent Athletes
}

\author{
Atcharat Yongtawee, Min-Jung Woo \\ School of Exercise and Sport Science, University of Ulsan, Ulsan, Korea
}

PURPOSE: Purposes of this study were to examine the differences in cognitive functions according to sports type and gender, and the relationship between training experience, sports type, gender and cognitive functions.

METHODS: Participants were 147 middle and high school students consisting of 63 interceptive and 84 static sport athletes. Cognitive functions were measured by using the choice reaction time (CRT), concentration grid test (CGT), Purdue spatial visual test (PSVT), and digit symbol substitution test (DSST).

RESULTS: CRT reaction time in male athletes was significantly accelerated as the training experience in the interceptive sport increases. The longer training experience of static sports, the lower DDST score in men, which means that it takes longer to match numbers and signs. However, the relationships between training experience and CRT, DSST were not significant in female. The significant gender differences were found on CRT, CGT, and PSVT, DSST with female athletes showing higher score on the DSST, accuracy of CRT and CGT but a slower response time to PSVT compared to the male ones.

CONCLUSIONS: Faster reaction time with increasing training experience in interceptive sport can be viewed as an effect of continuous interceptive training that involves mental effort to rapidly respond to a stimulus. The delayed processing speeds with increasing training experience in static sport seem to support the notion of speed-accuracy trade-off. The fact that the relationship between training experience and cognitive functions were only significant in male athletes implies that the gender, which is influenced by the speedaccuracy trade-off phenomenon by sport training, is male.

Key words: Cognitive functions, Gender, Sports types, Training experience, Athlete

\section{INTRODUCTION}

Sports Ministries in many countries including Hong Kong, Japan and Australia, participated in a project for athlete talent identification and development to enhance global competitiveness in elite sports. The variables measured to identify gifted young athletes were limited to physical, physiological, anthropometrical, technical and genetic factors [1]. Recently, sports psychologists have emphasized that cognitive functions in elite athletes is also a crucial factor for peak performance in sports. According to a study by Vestberg et al. [2], the better the cognitive functions athletes have, including their working memory, spatial attention, divided attention, and information processing speed, the better their sports per- formance. Expert athletes are reported to have better memory, attention, perception, anticipation and decision-making skills than non-experts [35]. Similarly, Huijgen et al. [6] reported that elite youth soccer players outperformed sub-elite players on executive function tests which examined higher order cognitive processes, including attentional control, inhibitory control, working memory, reasoning, problem solving and planning. Cona et al. [7] also showed that faster ultra-marathoners are more effective in motor inhibition, a subcomponent of executive function, relative to slower runners. Therefore, it seems that cognitive functions are tightly related to sport performance.

Recently, it has been suggested that there may be specialized cognitive functions for certain types of sports. A meta-analysis study showed that

Corresponding author: Min-Jung Woo Tel +82-52-259-2380 Fax+82-52-259-1696 E-mail mjwoolaulsan.ac.kr

Received 27 Apr 2017 Revision 5 May 2017 Accepted 15 May 2017

(a) This is an Open Access article distributed under the terms of the Creative Commons Attribution Non-Commercial License (http://creativecommons.org/licenses/by-nc/4.0/) which permits unrestricted non-commercial use, distribution, and reproduction in any medium, provided the original work is properly cited. 
interceptive (e.g. tennis) and strategic sport (e.g. soccer) athletes perform better than static sport (e.g. shooting) ones in terms of processing speed [8]. Wang et al. [9] also revealed that open skill sport (tennis) athletes have superior inhibition control compared to closed skill sport (swimmers) athletes and sedentary persons. In addition, Jacobson and Matthaeus [3] found that self-paced athletes (e.g. bowling or running) scored higher on an inhibition task than externally paced ones (racquet and team sports) and non-athletes, but externally paced athletes scored higher on a problem solving task. These results imply the existence of cognitive functions which are selectively beneficial according to the types of sports. Those cognitive abilities showing significant differences depending on the types of sports were the processing speed skill, inhibitory control, and problem solving. The cause of the selective benefit for cognitive functioning according to the types of sports is speculated to be related to the following two possibilities 1) that athletes scoring higher on specific cognitive functions are prone to show superior ability in the corresponding sports, and 2) that long-term training in a sport may enhance the relevant cognitive functions.

In practice, a significant correlation between sport training experience and cognitive functions has been revealed. A study examining the influence of skill level and training experience on psychomotor ability targeting judo athletes revealed that the senior group who had longer training experience showed higher cognitive performance than the junior group, and the more highly skilled group obtained better cognitive scores than the less skilled group. It has also been shown that training experience has a significant correlation with psychomotor skills in judo players [10]. This result implies that long term training in sports enhances cognitive abilities relevant to the types of sports. That is, superiority of cognitive functions seems to be influenced by both the types of sports and the length of sport training.

There is another significant variable that affects cognitive functions, which is gender. Gur et al. [11] explained that the gender difference in brain structure leads to sex-related differences in cognitive functioning. Specifically, males, having a greater amount of white matter in the right hemisphere, tend to perform better on spatial tasks, whereas women, having thicker gray matter in the left hemisphere, show more effective verbal ability. Many studies have also found that men exhibit better performance in terms of mental rotation [12], reaction time [13] and visualspatial ability [14]. In contrast, women exhibit superior memory [15], verbal task, and information processing abilities [16]. In spite of these clear sex-related differences in cognitive functions, only few studies have ex- amined the impact of gender on cognitive skills in a sports context. A meta-analysis study which examined the relationship between expertise in sports and laboratory-based measures of cognitions reported that gender significantly accounted for heterogeneity, with males having a greater effect size for cognitive measures than females [8]. A study of Jansen and Lehmann [17] demonstrated that both male non-athletes and male athletes (soccer and gymnastics) showed better performance on a mental rotation task than female non-athletes and female athletes practicing the same sport.

Interestingly, the results of Moreau et al. [18] investigating the effect of sport training on mental rotation were consistent with those of Jansen and Lehmann [17]. They found that male wrestlers and runners outperformed female athletes practicing the same sport in the pretest and posttest, although a 10-month sport-specific practice program led to a significant improvement of mental rotation in both sexes and for both sports. In contrast, female wrestlers and taekwondo athletes showed better performance on a concentration task [19] and faster reaction time [20] than the male ones, respectively. However, there is also a study suggesting the absence of any gender differences in terms of the visual-spatial abilities of volleyball and tennis players [14]. In spite of their controversial results, gender seems to be a critical component which influences cognitive function and interacts with the types of sports.

Therefore, the purposes of this study were to determine if there is a significant difference in cognitive functions depending upon the types of sports and gender, if there is a relationship between cognitive functions and training experience, and if this relationship differs based on the types of sports. Our final goal is to provide a supplementary tool for the identification of talented individuals who are cognitively prepared for sport.

\section{MATERIALS AND METHODS}

\section{Participants}

The participants were 147 middle-high school athletes, including 84 static and 63 interceptive sports ones. The static sport participants included 27 athletics, 16 swimming, 3 rhythmic gymnastics, 4 artistic gymnastics, 4 weight lifting, 10 archery, 5 shooting, 6 canoe, 7 triathlon, 1 roller and 1 javelin athletes. The interceptive sport participants included 11 wrestling, 16 judo, 28 taekwondo, 7 boxing and 1 soft tennis athletes. The participants' characteristics are shown in (Table 1). 
Table 1. Age, Height, Weight, BMI and Training experience of participants

\begin{tabular}{|c|c|c|c|c|}
\hline & \multicolumn{2}{|c|}{ Gender } & \multicolumn{2}{|c|}{ Sport types } \\
\hline & $\begin{array}{c}\text { Male } \\
\text { Mean } \pm \text { SD }\end{array}$ & $\begin{array}{c}\text { Female } \\
\text { Mean } \pm \text { SD }\end{array}$ & $\begin{array}{c}\text { Static } \\
\text { Mean } \pm \text { SD }\end{array}$ & $\begin{array}{c}\text { Interceptive } \\
\text { Mean } \pm \text { SD }\end{array}$ \\
\hline Age (year) & $15.68 \pm 1.58$ & $15.16 \pm 1.53$ & $15.28 \pm 1.54$ & $15.79 \pm 1.61$ \\
\hline Height $(\mathrm{cm})$ & $171.54 \pm 8.81$ & $162.75 \pm 5.61$ & $167.88 \pm 9.74$ & $169.16 \pm 7.58$ \\
\hline Weight (kg) & $65.45 \pm 13.62$ & $59.22 \pm 10.54$ & $61.50 \pm 13.32$ & $65.57 \pm 12.10$ \\
\hline
\end{tabular}

\section{Materials}

The participants performed 4 cognitive function tasks: 3 computerized tests (choice reaction time, concentration grid test and Purdue spatial visualization task) and one paper-pencil test (digit symbol substitution test)

\section{1) Choice Reaction time Test (CRT)}

CRT was administered to measure the information processing speed [21]. The CRT consists of 60 stimuli made up of 20 red, 20 blue, and 20 yellow circles. The stimuli were randomly presented one at a time on a computer screen. The participants were instructed to press the appropriate button corresponding to the stimuli presented at one second intervals as quickly and accurately as possible. Specifically, the participants needed to press the left, right or no button in response to the red, blue, or yellow circles on the screen, respectively. The percentage of correct answers (accuracy) and mean reaction time (RT) of the total correct answers were calculated for the analysis.

\section{2) Concentration Grid Test (CGT)}

CGT was developed to assess attention, concentration and memory [22]. This test is comprised of numbers from 00 to 99 . All of the digits were placed randomly in one of the $10 \times 10$ numerical grids on a computer screen. The participants were asked to search for consecutive numbers in the range from 00 to 99 and respond by clicking on the grid with the mouse as quickly and accurately as possible. The completion time and accuracy on the CGT were automatically calculated and saved for further analysis.

\section{3) Revised Purdue Spatial Visualization Tests: Visualization of Rotations (Revised of PSVT: R)}

PSVT [23] was employed to determine the spatial visualization ability, a subcomponent of spatial ability (skills needed to generate, retain, re- trieve, and transform abstract visual images; [24]). The test consisted of 30 questions including 13 symmetrical and 17 asymmetrical 3-D cube or cylinder shape objects with varied truncated slots. The participants were asked to select the same figure as that in a given example among 5 choices for each item, in which the figure was rotated so as to have a different direction and angle, without a time limit. The next question was displayed on the computer screen and moved to the right after pressing the button. The accuracy (\%), and average response time of correct answers were calculated.

\section{4) Digit Symbol Substitution Test (DSST)}

DSST was used to measure the information processing ability [25]. The paper-pencil version of the DSST was employed in the present study. This test consists of nine digit-symbol codes that appeared on the top of the test sheet. The participants were required to fill in a small box with the symbols corresponding to the numbers (1-9) as accurately and quickly as possible in 120 seconds. The numbers of correct answers were recorded.

\section{Procedures}

All of the participants were informed of the purpose of the experiment and signed the informed consent. The test was conducted in a quiet computer room. The participants were asked to complete four cognitive tests, including the choice reaction time test, concentration grid test, Purdue spatial visualization task and digit symbol substitution test to the best of their ability. The three computerized tests, which were displayed in randomized order, were followed by the paper-pencil test. Prior to the actual test, 3 practice trials for each test were provided to make sure the participants understood them.

\section{Statistical analysis}

Simple linear regression analyses were also used to determine if train- 
ing experience is a significant predictor of 7 dependent variables of cognitive functions according to sports type, gender, and gender of each sport type. The assumptions of normal distribution of all variables were examined using the Kolmogorov-Smirnov test. To evaluate the differences in cognitive functions (accuracy and reaction time on the CRT, accuracy and completion time on the CGT, accuracy and response time on the PSVT, and total score on the DSST) depending on the gender and sports types, a 2 (gender) $\times 2$ (sports type) factorial multivariate analysis of variance (MANOVA) was conducted. A univariate analysis of variance test was conducted to follow up on the significant main effects. The level of significance was $\alpha=.05$. All statistical analyses were conducted using SPSS.

\section{RESULTS}

The simple linear regression analysis examining the relationship between training experience and cognitive functions according to sport type revealed that training experience was positively correlated with CRT-RT in the case of interceptive sports $\left(\mathrm{R}^{2}=.066, p=.035\right)$, but negatively correlated with CRT-RT in the case of static sports $\left(\mathrm{R}^{2}=.059\right.$, $p=.026$ ). Furthermore, training experience were also negatively correlated with the total score on the DSST $\left(\mathrm{R}^{2}=.055, p=.032\right)$ in static sports. There were no significant associations between training experience and other cognitive functions in either type of sports.

The regression analysis examining the relationship between training experience and cognitive functions according to gender revealed that the training experience was negatively correlated with DSST score $\left(\mathrm{R}^{2}=.043\right.$,

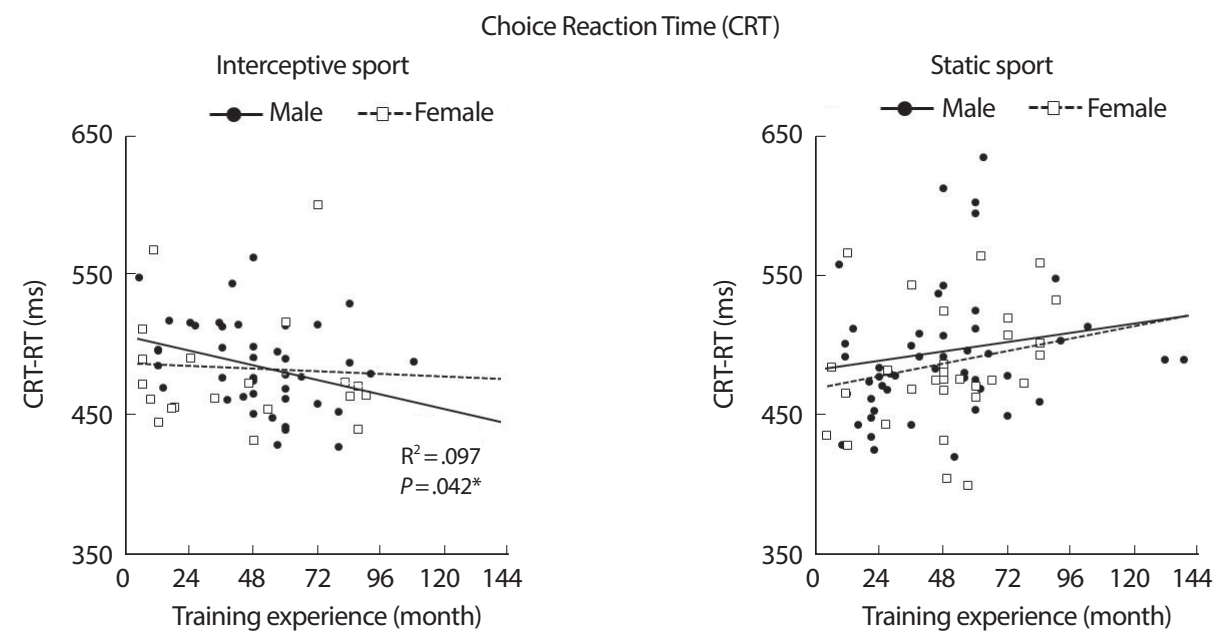

Fig. 1. Scatter plot of training experience and reaction time of CRT of male and female athletes in interceptive and static sports $\left({ }^{*} p<.05\right)$.

Digit Symbol Substitution Test (DSST)
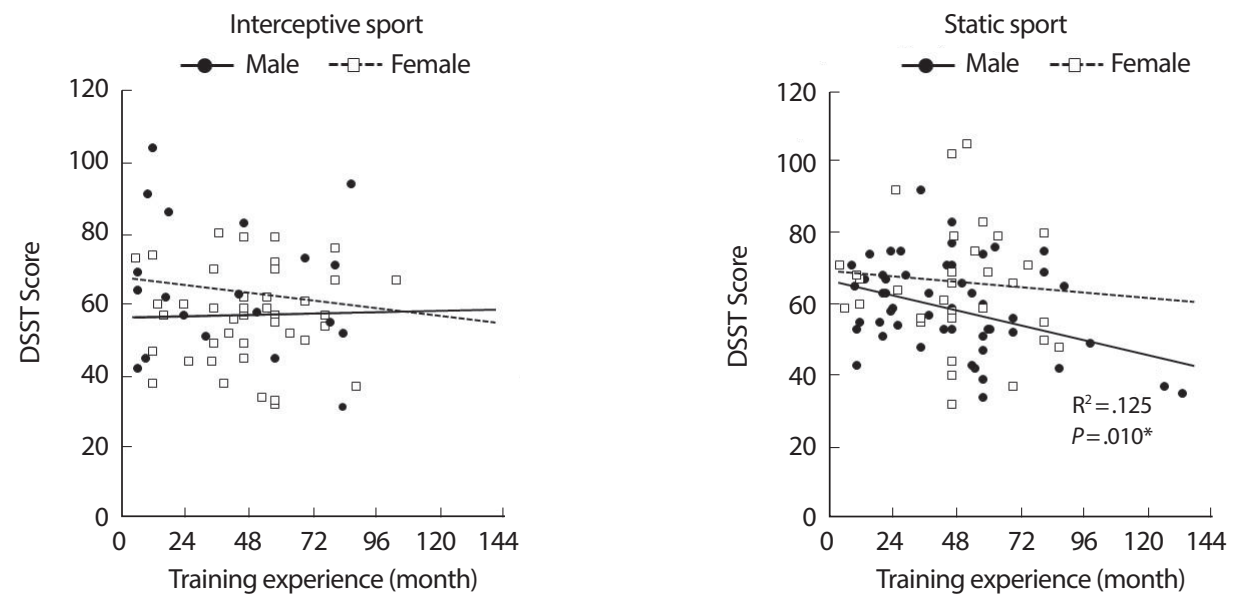

Fig. 2. Scatter plot of training experience and total score of DSST of male and female athletes in interceptive and static sports ( $\left.{ }^{*} p<.05\right)$. 
Table 2. Simple linear regression between training experience and cognitive functions in male and female athletes of interceptive and static sports

\begin{tabular}{|c|c|c|c|c|c|c|c|c|}
\hline \multicolumn{2}{|c|}{ Cognitive functions } & Sport type & Gender & B & $\mathrm{R}^{2}$ & $\mathrm{df}$ & $\mathrm{F}$ & $p$ \\
\hline \multirow[t]{8}{*}{ CRT } & Accuracy (\%) & Interceptive & Male & -.107 & .011 & 1,41 & .474 & .495 \\
\hline & & & Female & -.242 & .059 & 1,18 & 1.124 & .303 \\
\hline & & Static & Male & -.079 & .006 & 1,50 & .313 & .578 \\
\hline & & & Female & .182 & .033 & 1,30 & 1.024 & .320 \\
\hline & Reaction time (ms) & Interceptive & Male & -.312 & .097 & 1,41 & 4.421 & $.042^{*}$ \\
\hline & & & Female & -.055 & .003 & 1,18 & .054 & .819 \\
\hline & & Static & Male & .23 & .053 & 1,50 & 2.803 & .100 \\
\hline & & & Female & .286 & .082 & 1,30 & 2.670 & .113 \\
\hline \multirow[t]{8}{*}{ CGT } & Accuracy (\%) & Interceptive & Male & .106 & .011 & 1,41 & .470 & .497 \\
\hline & & & Female & .341 & .116 & 1,18 & 2.367 & .141 \\
\hline & & Static & Male & -.242 & .059 & 1,50 & 3.121 & .083 \\
\hline & & & Female & -.013 & .000 & 1,30 & .005 & .942 \\
\hline & Completion time (s) & Interceptive & Male & -.205 & .042 & 1,41 & 1.796 & .188 \\
\hline & & & Female & .015 & .000 & 1,18 & .004 & .950 \\
\hline & & Static & Male & .066 & .004 & 1,50 & .217 & .643 \\
\hline & & & Female & -.056 & .003 & 1,30 & .095 & .760 \\
\hline \multirow[t]{8}{*}{ PSVT } & Accuracy (\%) & Interceptive & Male & .209 & .044 & 1,41 & 1.872 & .179 \\
\hline & & & Female & -.101 & .010 & 1,18 & .185 & .673 \\
\hline & & Static & Male & -.036 & .001 & 1,50 & .067 & .797 \\
\hline & & & Female & .276 & .076 & 1,30 & 2.467 & .127 \\
\hline & Response time (s) & Interceptive & Male & .119 & .014 & 1,41 & .584 & .449 \\
\hline & & & Female & .182 & .033 & 1,18 & .614 & .443 \\
\hline & & Static & Male & -.024 & .001 & 1,50 & .028 & .868 \\
\hline & & & Female & .031 & .001 & 1,30 & .029 & .867 \\
\hline \multirow[t]{4}{*}{ DSST } & Score & Interceptive & Male & .025 & .001 & 1,41 & .026 & .874 \\
\hline & & & Female & -.149 & .022 & 1,18 & .409 & .530 \\
\hline & & Static & Male & -.354 & .125 & 1,50 & 7.144 & $.010^{*}$ \\
\hline & & & Female & -.088 & .008 & 1,30 & .232 & .633 \\
\hline
\end{tabular}

${ }^{*} p<.05$.
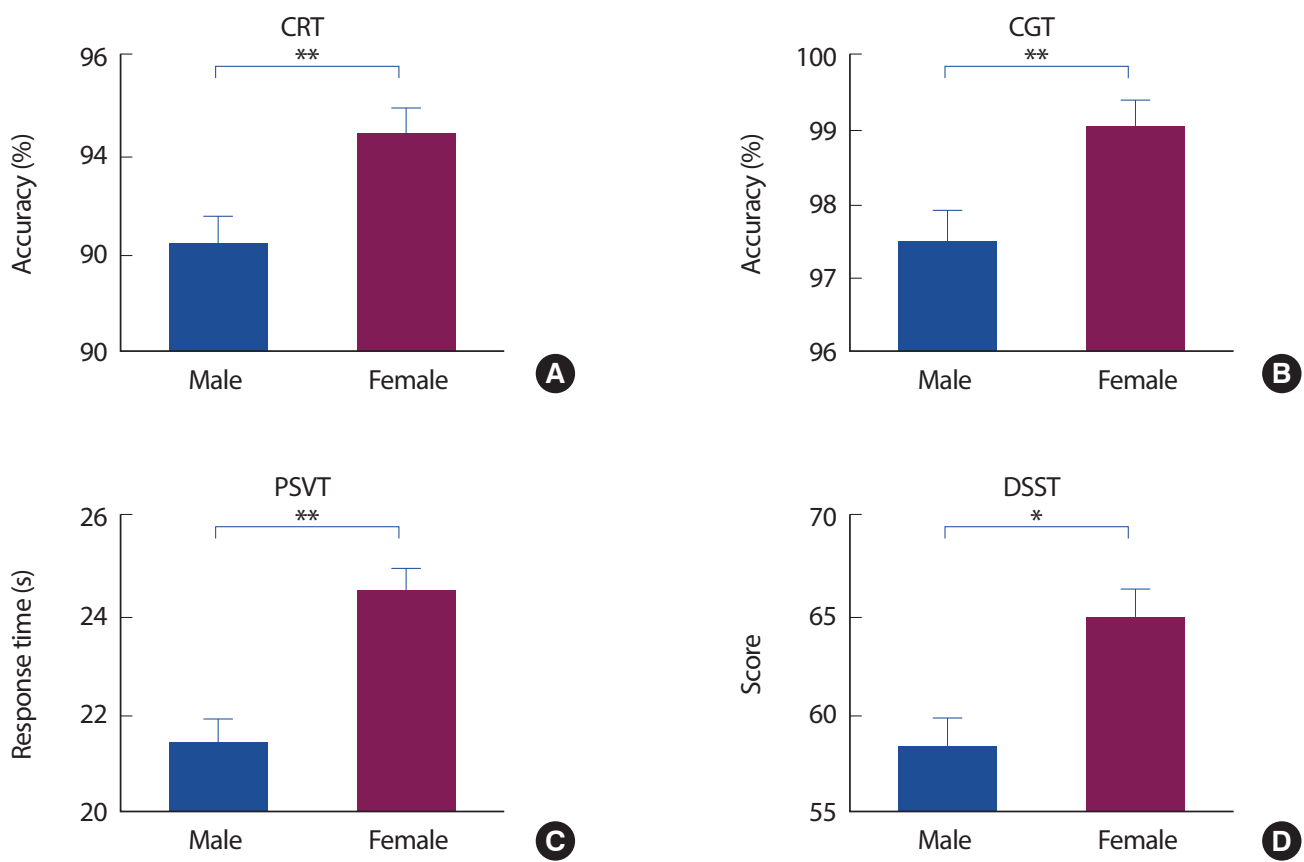

Fig. 3. (A) Accuracy rate of CRT, (B) Accuracy rate of CGT, (C) Response time of PSVT and (D) Total score of DSST of male and female athletes ( $\left.{ }^{*} p<.05,{ }^{* *} p<.01\right)$. 
$p=.045)$ in male athletes, but not in female athletes. However, there were no such significant correlation between training experience and other sub-domains of cognitive functions regardless of gender.

The regression analysis examining the relationship between training experience and cognitive functions according to gender of each sports type revealed that there was a negative correlation between CRT-RT and training experience of interceptive sports in male athletes $\left(\mathrm{R}^{2}=.097\right.$, $p=.042$ ), but not in females as shown in Fig. 1. Such relationships above were not observed in static sports. Moreover, in male athletes of static sports, the significant negative correlation between total score of DSST and training experience was observed $\left(\mathrm{R}^{2}=.125, p=.010\right)$, but was not appeared in females as presented in Fig. 2. However, there were no such relations were found in interceptive sports. Besides, the significant relationship between training experience and other subcomponents of cognitive performances, CGT and PSVT were not found without regarding gender and sports types (Table 2). Analysis of the Kolmogorov-Smirnov indicated that the cognitive variables showing the relationship with training experience were normally distributed.

The results of the MANOVA revealed a significant main effect of gen$\operatorname{der}\left(\mathrm{F}_{13,131}=8.19, p<.001, \lambda=.551\right)$. Post hoc analysis demonstrated that the female athletes had higher accuracy on the CRT $\left(\mathrm{F}_{13,143}=8.112, p=\right.$ $.005)$ and CGT $\left(\mathrm{F}_{13,143}=9.205, p=.003\right)$ and a higher score on the DSST $\left(\mathrm{F}_{13,143}=6.691, p=.011\right)$ compared to the male athletes, whereas the male athletes showed a faster response time on the PSVT $\left(\mathrm{F}_{13,143}=7.950\right.$, $p=.005$ ) (Fig. 3). However, there were no gender differences in the choice reaction time, completion time of the CGT or accuracy of the PSVT. The main effect of sports types, and the interaction between gender and sports types were not significant.

\section{DISCUSSION}

This study examined the relationship between training experience and cognitive functions according to sports type, gender, and gender of each sports type. The regression analysis revealed that training accounts for a significant amount of the variance of the choice reaction time (CRT) and digit symbol substitution test score (DSST). Notably, the direction of the relationship between training experience and CRT and DSST differed depending on the sports type, gender, and gender of each sports type.

The simple linear regression analysis examining the relationship between training experience and cognitive functions according to sport type revealed that the training experience was negatively related to CRT in interceptive sports, but positively related to CRT in static sports. In interceptive sports, CRT is the only variable that shows a significant relationship with training experience, and an increase in experience causes a shortening of the RT, which is consistent with the result of previous meta-analyses, in which "interceptive sports showed the largest statistically significant effect on measures of processing speed" [5,8]. In addition, Mann et al. [5] reported that the relationship between the level of expertise of athletes and their response time varies with the sports. Specifically, expert athletes in interceptive and strategic sports exhibited faster RTs than their less skilled counterparts. However, there was no difference in RT according to the level of skill in other sports. Athletes in sports where interceptive actions are predominant showed the greatest benefit on measures of processing speed.

Since previous studies which examined the difference in processing speed depending on the level of skill or sports types were cross-sectional ones, it is still unclear whether the faster processing speed found in interceptive sport athletes relative to athletes in strategic or static sports is the result of training or due to their natural talent in terms of processing speed. However, recent studies which investigated the processing speed of interceptive sport athletes with different sports experience reported that more experienced athletes had a faster processing speed than less experienced ones $[10,26]$. In the present study, the interceptive sport athletes exhibited a reduction in their processing speed with increasing training experience. Such results support the hypothesis that interceptive sport training reduces processing speed.

Then, what creates the beneficial effect of interceptive sport training on processing speed? Interceptive sport is a type of sport that includes the characteristics of aerobic exercise and competitive sports. A metaanalysis on the effect of aerobic exercise on cognitive functions revealed the benefits of aerobic exercise in terms of executive functions, visuospatial processing, controlled processing, and processing [27]. In the present study, however, the relationship between training experience in interceptive sports and cognitive functions was only significant in regards to the choice reaction time. This may be due to the nature of interceptive sports that involves mental demands requiring rapid reaction to the stimulus.

Contrary to interceptive sports, static sports exhibited delayed reaction time with increasing training experience. Mann et al. [5] observed a smaller effect on response time in static sport athletes than in other sports types. Sports were defined as static if they involved highly consistent, self-paced situations [8]. For this reason, static sport training is con- 
centrated more on the enhancement of accuracy and consistency than improving prompt response to stimuli in a rapidly changing environment. In shooting and archery, for example, physical fixation training is conducted to minimize body movements.

As found in this study, long-term training to enhance accuracy and consistency may lead to a reduction in processing speed, which can be understood in terms of a speed-accuracy trade-off. This speed-accuracy trade-off expresses the negative relationship between speed and accuracy, which is a phenomenon in which speed increases as accuracy decreases and vice versa [28]. As a fundamental principle of human performance, the speed-accuracy trade-off was refers to either when the people try to perform faster response with a large number of error rate or slower in decision making or movement responding but make more accurate [21]. Therefore, it is possible that the long-term physical fixation training of static sport athletes to increase their accuracy leads to a delay in their processing speed.

The negative relationship between processing speed and training experience in static sport athletes was also found in the digit-symbol substitution test (DSST). The DSST scores showed strong correlations with measures that in some way involve perceptual speed or processing speed $[29,30]$. A higher DSST score reflects faster perceptual or processing speed. The static sport athletes exhibited lower DSST scores as their training experience increased. This decline in processing speed can be seen as a counteraction to increased accuracy resulting from long-term training in of static sports.

As shown in the choice reaction time test and the symbol digit substitution test, the static sport athletes exhibited a delay in their processing speed with increasing training experience. Importantly, however, it cannot be concluded that a slow reaction time is beneficial in static sports. Even though static sport training has a tendency to slow the processing speed, it is unclear whether such delay in processing speed is beneficial to sport performance. Thus, a broader population of static sport athletes must be examined to determine the difference in processing speed according to the level of skill.

The regression analysis examining the relationship between training experience and cognitive functions according to gender of each sports type revealed that the reaction time in male athletes was significantly accelerated as the training experience increases in the interceptive sports as shown in Fig. 1, which requires quick judgment and response, but the relationship was not significant in female. On the other hand, the longer the training experience of the static sports, the lower the DDST score in men (Fig. 2), which means that it takes longer to match numbers and signs. These results implies that the longer the training experience of static sports such as shooting and archery, which is the most important goal of improving accuracy, the slower the information processing speed of men. It means that the gender, which shows the speed-accuracy tradeoff phenomenon by the training of the sport, is male. It is well known that prenatal testosterone levels yields gender differences in brain [31]. It has been also proven that there is a gender differences in brain and cognitive function. For example, women are known to have better language perception [32], and fine motor skills [33], in which accuracy is important, whereas men are capable of spatial perception [34], or motor skills [35]. In fact, testosterone has been shown to improve blood circulation in the brain areas, which are responsible for strategic planning, arousal state, memory and complex motor behavior [36,37].

The MANOVA to examine the influence of gender and sports type on cognitive function revealed sex-related differences in cognitive functions, as shown in Fig. 3. The females showed higher accuracy on the choice reaction time (CRT) test, and concentration grid test (CGT) and a slower response time on the Purdue spatial visual test (PSVT), relative to the males. Barral and Debu [38] examining sex-related difference in motor control revealed that women were globally slower and more accurate than men. Similar results were replicated with females showing higher accuracy on the CRT [38] and CGT [19] and a slower response time on the PSVT [39] relative to males. Barrel and Debu [38] insisted that such gender differences could result from a sex-related difference in the neural mechanism of movement control, namely that females take advantage of their slower movements to process a greater amount of movement-produced feedback and achieve greater accuracy. This is a plausible cause of the higher accuracy but slower response to the cognitive tests observed in the female participants in the present study.

The score on the digit symbol substitution test (DSST) was higher in the females than the males. This result is consistent with previous studies showing that the performance on the Digit-Symbol subtest typically favors females with medium effect sizes (Cohen's $d=0.5$; [40]). The female advantage on the DSST is claimed to be explicable in terms of sex differences in rapid recognition, attentional shifting or information processing capacity [41]. Likewise, this clear sex-related difference in cognitive functions implies that gender should be considered as a meaningful variable influencing sport type-related cognitive function.

In the present study, no significant difference in cognitive function was found depending on sports types. This may be due to the length of 
time being insufficient to have cognitive benefits from long-term training, as the participants of this study were junior athletes with an average of 4 years of experience. In future studies, it will be necessary to examine elite athletes with longer career experience or with expert skill levels, in order to see if there is a cognitive function specific to certain sports types. A more accurate investigation of the effect of training on cognitive function would require a longitudinal study, observing the changing process of cognitive function in beginners resulting from long-term training in the sports.

\section{CONCLUSION}

A faster reaction time with increasing training experience in interceptive sport can be viewed as an effect of continuous interceptive training that involves mental effort to rapidly respond to a stimulus. On the other hand, the delayed processing speeds with increasing training experience in static sport seem to imply that the physical training they undergo to improve consistency and accuracy may delay their processing speed as a counteraction according to the speed-accuracy trade-off. The fact that the relationship between training experience and cognitive functions were only significant in male athletes implies that the gender, which is influenced mostly by the speed-accuracy trade-off phenomenon by the training of the sport, is male.

\section{REFERENCES}

1. Legislative Council Secretariat of Hong Kong. Research Report Olympic committees, sports federations and sports development in selected places. 2016 October 30; Retrieved from: http://www.legco.gov.hk/research-publications/english/1415rp02-olympic-committees-sportsfederations-and-sports-development-in- selected-places-20150203-e. pdf

2. Vestberg T, Gustafson R, Maurex L, Ingvar M, Petrovic P. Executive functions predict the success of top-soccer players. PLoS ONE 2012; 7(4):e34731.

3. Jacobson J, Matthaeus L. Athletics and executive functioning: How athletic participation and sport type correlate with cognitive performance. Psychology of Sport and Exercise 2014;15(5):521-527.

4. Starkes JL, Ericsson KA. Expert performance in sports: Advances in research on sport expertise. 1st ed., Champaign, IL: Human Kinetics 2003.
5. Mann DTY, Williams AM, Ward P, Janelle CM. Perceptual-cognitive expertise in sport: a meta-analysis. Journal of Sport \& Exercise Psychology 2007;29(4):457-477.

6. Huijgen BCH, Leemhuis S, Kok NM, Verburgh L, Oosterlaan J, et al. Cognitive functions in elite and sub-elite youth soccer players aged 13 to 17 years. PLoS ONE 2015;10(12):e0144580.

7. Cona G, Cavazzana A, Paoli A, Marcolin G, Grainer A, et al. It's a matter of mind! cognitive functioning predicts the athletic performance in ultra-marathon runners. PLoS ONE. 2015;10(7):e0132943.

8. Voss MW, Kramer AF, Basak C, Prakash RS, Roberts B. Are expert athletes 'expert'in the cognitive laboratory? A meta-analytic review of cognition and sport expertise. Applied Cognitive Psychology 2010; 24(6):812-826

9. Wang CH, Chang CC, Liang YM, Shih CM, Chiu WS, et al. Open vs. closed skill sports and the modulation of inhibitory control. PLoS ONE 2013;8(2):e55773.

10. Supinski J, Obminski Z, Kubacki R, Kosa J, Moska W. Usefulness of the psychomotor tests for distinguishing the skill levels among older and younger judo athletes. Archives of Budo 2014;1(10):315-322.

11. Gur RC, Turetsky BI, Matsui M, Yan M, Bilker W, et al. Sex differences in brain gray and white matter in healthy young adults: correlations with cognitive performance. Journal of Neuroscience 1999;19(10): 4065-4072.

12. Li R, Singh M. Sex differences in cognitive impairment and Alzheimer's disease. Frontiers in Neuroendocrinology 2014;35(3):385-403.

13. Dykiert D, Der G, Starr JM, Deary IJ. Sex differences in reaction time mean and intraindividual variability across the life span. Developmental Psychology 2012;48(5):1262-1276.

14. Notarnicola A, Maccagnano G, Pesce V, Tafuri S, Novielli G, et al. Visual-spatial capacity: gender and sport differences in young volleyball and tennis athletes and non-athletes. BMC Research Notes 2014;7(57): $1-5$.

15. Hampson E, Kimura D. Sex differences and hormonal influence on cognitive function in humans. In: Becker JB, Breedlove SM, Crews D, editors. Behavioral endocrinology. Cambridge, MA: MIT Press/Bradford Books 1992;357-398

16. Weiss EM, Kemmler G, Deisenhammer EA, Fleischhacker WW, Delazer M. Sex differences in cognitive functions. Personality Individual Differences 2003;35(4):863-875.

17. Jansen P, Lehmann J. Mental rotation performance in soccer players and gymnasts in an object-based mental rotation task. Advances in 
Cognitive Psychology 2013;9(2):92-98.

18. Moreau D, Clerc J, Mansy-Dannay A, Guerrin A. Enhancing spatial ability through sport practice. Journal of Individual Differences 2012; 33(2):83-88.

19. Bhardwaj S, Singh N, Rathee N. A qualitative study of mental perseverance and mental concentration among elite and sub-elite wrestlers. European Scientific Journal 2014;10(8):202-209.

20. Ervilha UF, Silva VF, Araújo CR, Mochizuki L, Hamill J. Elite female tae kwon do athletes have faster reaction time and longer movement time than males during a striking kick. Archives of Budo Science of Martial Arts and Extreme Sports 2014;10:1-9.

21. Schmidt RA, Lee TD. Motor learning and performance. 5th ed., Champaign, IL: Human Kinetics Publishers 2014.

22. Harris DV, Harris BL. The athlete's guide to sports psychology: Mental skills for physical people. New York: Leisure Press 1984.

23. Yoon SY. Psychometric properties of the Revised Purdue Spatial Visualization Tests: Visualization of Rotations (The Revised PSVT:R) [dissertation]. Indiana: Purdue University 2011.

24. Lohman DF. Spatial abilities as traits, processes, and knowledge. In: Sternberg RJ, Editor. Advances in the psychology of human intelligence. Hillsdale, NJ: Erlbaum 1988;181-248.

25. Wechsler, D. WMS-III: Wechsler memory scale administration and scoring manual. 3rd ed., San Antonio, TX: The Psychological Corporation 1997.

26. Vidja KR, Bhabhor MK, Sarvaiya JL, Patel NS, Joshi V. Long term playing of badminton improves the visual reaction time. International Journal of Research in Medical Sciences 2015;4(1):90-92.

27. Colcombe S, Kramer AF. Fitness effects on the cognitive function of older adults: A meta-analytic study. Psychological Science 2003;14 (2):125-130

28. Garrett HE. A study of the relation of accuracy to speed. Archives of Psychology 1922;56:1-104.

29. Salthouse TA. Aging and measures of processing speed. Biological Psychology 2000;54(1):35-54.
30. Sliwinski M, Buschke H. Cross-sectional and longitudinal relationships among age, cognition, and processing speed. Psychology and Aging 1999;14(1):18-33.

31. Baron-Cohen S, Knickmeyer RC, Belmonte MK. Sex differences in the brain: implications for explaining autism. Science 2005;310(5749): 819-823.

32. Kimura D. Sex and Cognition. Cambridge, MA: MIT Press 1999.

33. Hall J, Kimura D. Sexual orientation and performance on sexually dimorphic motor tasks. Archives of Sexual Behaviour 1995;24(4):395-407.

34. Linn MC, Petersen AC. Emergence and characterization of gender differences in spatial abilities: A meta analysis. Child Development 1985;56(6):1479-1498.

35. Barnett LM, van Beurden E, Morgan PJ, Brooks LO, Beard JR. Gender differences in motor skill proficiency from childhood to adolescence: A longitudinal study. Research quarterly for exercise and sport 2010; 81(2):162-170

36. Krause DN, Duckles SP, Pelligrino DA. Influence of sex steroid hormones on cerebrovascular function. Journal of applied physiology 2006;101(4):1252-1261

37. Nguyen TV, Lew J, Albaugh MD, Botteron KN, Hudziak JJ, et al. Sexspecific associations of testosterone with prefrontal-hippocampal development and executive function. Psychoneuroendocrinology 2017; 76:206-217.

38. Barral J, Debu B. Aiming in adults: Sex and laterality effects. Laterality 2004;9(3):299-312.

39. Goldstein D, Haldane D, Mitchell C. Sex differences in visual-spatial ability: the role of the performance factors. Memory and Cognition 1990;18(5):546-550.

40. Herlitz A, Yonker JE. Sex differences in episodic memory: The influence of intelligence. Journal of Clinical and Experimental Neuropsychology 2002;24(1):107-114.

41. Royer FL. Information processing of visual figures in the digit symbol substitution task. Journal of Experimental Psychology 1971;87(3):335342. 